\title{
In vitro Cell Proliferation Assay of Demineralized Dentin Material Membrane in Osteoblastic MC3T3-EI Cells
}

\author{
Pratiwi Soesilawati (D) ${ }^{1-4}$ \\ Andra Rizqiawan ${ }^{4,5}$ \\ Retno Indrawati Roestamadji,3 \\ Ahmad Rizal Arrosyad ${ }^{6}$ \\ Muhammad Alwino Bayu \\ Firdauzy ${ }^{3,6}$ \\ Noor Hayaty Abu Kasim 7,8 \\ 'Department of Oral Biology, Faculty of \\ Dental Medicine, Universitas Airlangga, \\ Surabaya, Indonesia; ${ }^{2}$ Cell and Tissue \\ Bank-Regenerative Medicine, \\ Dr Soetomo General Academic Hospital/ \\ Faculty of Medicine, Universitas \\ Airlangga, Surabaya, Indonesia; \\ ${ }^{3}$ Immunology Program, Postgraduate \\ School, Universitas Airlangga, Surabaya, \\ Indonesia; ${ }^{4}$ Dental Hospital, Universitas \\ Airlangga, Surabaya, Indonesia; \\ ${ }^{5}$ Department of Oral and Maxillofacial \\ Surgery, Faculty of Dental Medicine, \\ Universitas Airlangga, Surabaya, \\ Indonesia; ${ }^{6}$ Dental Profession Program, \\ Faculty of Dental Medicine, Universitas \\ Airlangga, Surabaya, Indonesia; ${ }^{7}$ Faculty of \\ Dentistry, University Kebangsaan \\ Malaysia, Kuala Lumpur, Malaysia; ${ }^{8}$ Faculty \\ of Dental Medicine, Universitas Airlangga, \\ Surabaya, Indonesia
}

Correspondence: Pratiwi Soesilawati Department of Oral Biology, Faculty of

Dental Medicine, Universitas Airlangga, JI

Mayjend Prof. Dr. Moestopo No. 47,

Surabaya, 60132, Indonesia

Tel +62315030255

Fax +62315030256

Email pratiwi-s@fkg.unair.ac.id
Aim: Demineralized dentin material membrane (DDMM) is a novel bioresorbable guided bone regeneration (GBR) which is derived from the demineralization process of bovine dentin. This material/process could be an alternative to resolve musculoskeletal dysfunction that harms the quality of human life.

Purpose: To evaluate the cytotoxic effect of DDMM as GBR membrane on MC3T3-E1 osteoblast cell line.

Methods: Cytotoxic effect was evaluated using the 3-(4,5-dimethylthiazol-2-yl)-2,5-diphenyltetrazolium bromide (MTT) assay. Osteoblast MC3T3-E1 cell culture was used as a parameter of cell viability after reacting with GBR materials. The absorbance values were examined at each treatment to determine the percentage of cell viability. There were four groups created in the present study: two treatment groups and two control groups. The treatment groups consisted of a DDMM group and a bovine pericardium collagen membrane (BPCM) group. The control groups comprised a group containing cell culture medium as a negative control group and another positive control group that contained cell cultures.

Results: The results revealed no significant difference in MC3T3-E1 cell viability between the treatment and control groups $(\mathrm{p}<0.05)$. Moreover, as observed in the DDMM group, there was an increase in the number of osteoblast cells.

Conclusion: DDMM is a suitable alternative biomaterial for GBR as it is non-cytotoxic and could potentially increase the rate of repair of craniofacial defects.

Keywords: cells, biomedical and dental materials, oral surgical procedures, materials testing, wound, injuries, cytotoxicity test, pre-prosthetic

\section{Introduction}

The scope of oral and craniofacial surgery includes various surgical procedures, such as tooth extraction, implants, removal of pathological infections in the oral cavity, cleft lip, palatal surgery, orthognathic surgery, and head-and-neck reconstructive surgery. The etiology of craniofacial defects is trauma, malignancy, and hereditary defects. In general, craniofacial defects will disrupt the function of chewing function, aesthetic function, and musculoskeletal dysfunction, which negatively affects the quality of human life. Rehabilitation of patients with craniofacial defects is necessary to restore lost functions. ${ }^{1}$

Scientists have found several techniques to reconstruct craniofacial defects, including bone grafting, bone splitting, and guided bone regeneration (GBR). Among the reconstruction techniques mentioned before, GBR is the chosen 
technique by many operators in dentistry. The medical community often chooses the GBR technique because it is considered more biocompatible and has been proven in almost all studies and medical procedures to reconstruct craniofacial defects, which proves increased tissue regeneration. $^{2}$

Guided Bone Regeneration has been widely circulating with various brands, including Bovine Pericardium Collagen Membrane (BPCM) and Demineralised FreezeDried Bovine Cortical Bone Membrane (DFDBCBM). The membranes have been tested for biocompatibility and shown promising results when applied to bone. ${ }^{3}$

Previous research using BPCM and DFDBCBM, on the other hand, revealed a number of flaws. After it observed, such as an increase in inflammatory cell invasion following the implantation of chemically cross-linked collagen and a high operational cost. ${ }^{3,4}$ Based on the reasons above, it is necessary to find an alternative type of biomedical dental material with similar structures and functions to significantly treat bone defects. This study attempted to discover the possibility of Bovine demineralized Dentine Material Membrane (DDMM). So, it can be used as a guided bone regeneration membrane. The organic matter in bovine dentine is similar to human dentine. Human teeth are the most mineralized tooth of all living creatures, and bovine enamel and dentine have the closest similarity to that of human. ${ }^{27}$ Dentine contains extracellular Type I collagen and various growth factors, such as bone morphogenetic proteins (BMP), Osteocalcin, Osteonectin, and Phosphoprotein, recognized to play a role in the mineralization of bones. ${ }^{1}$ Novel Bovine DDMM has several advantages because this material has growth factors like FGF, IGF-I, IGF-II, bFGF, and TGF- $\beta .^{4}$ Therefore, the use of DDMM as GBR is expected to improve bone healing. The first principle of any biomaterial is that it must be compatible with the host body. Biocompatibility is the ability of a material to adapt to the host not to harm the body. To examine the biocompatibility of a material, a cytotoxicity test is required to determine the effect of a substance on cells directly by MTT assay. ${ }^{6}$

\section{Materials and Methods Materials Examined}

The sample population of experimental groups were novel DDMM and BPCM (Jason Membrane ${ }^{\circledR}$, Botiss, Germany). This study used six replications from each group. In addition to the experimental groups, a control group was set under the same experimental condition, consisting of MC3T3-E1 osteoblast cell culture as a positive control group and a media as a negative control group. ${ }^{6,7}$

The first procedure was to prepare DDMM by collecting ten intact bovine teeth with an open apex that were then washed in tap water. The teeth were then refrigerated in $70 \%$ ethyl alcohol.

Next, they were rinsed before the removal of attached soft tissue and pulp.Bovine dentine was soaked in $3 \%$ hydrogen peroxide, which was replaced every day until the tissue became white. It was soaked in sterile distilled water for 5-6 days. Then, refluxed for 2 hours in isopropanol to eliminate any leftover of soft tissue or fat.

The dentine was cut and administered in a freezedrying process at $-80{ }^{\circ} \mathrm{C}$ in a freeze dryer container under vacuum pressure $(<20 \mathrm{~Pa})$ and dried for $18-24$ hours until the remaining water content was $5 \%$. The demineralization process used $0.6 \mathrm{~N} \mathrm{HCl}$. The tissue was cut into a $5 \times 5 \mathrm{~mm}$ square with a thickness of $300 \mu \mathrm{m}$. The double packing and sterilisation process were conducted using gamma irradiation. ${ }^{26,28}$ The present research was approved by Health Research Ethical Clearance Commission, Universitas Airlangga, Faculty of Dental, Number 780/HERCC.FODM/X/2020, and was conducted at the Research Center, Faculty of Dental Medicine, Universitas Airlangga, Surabaya, Indonesia.

\section{Cell Culture}

The MC3T3-E1 cells (ATCC, USA) were incubated in a humidified incubator with $95 \%$ humidity and $5 \%$ of $\mathrm{CO} 2$, immersed in the $\alpha$-Minimal Essential Medium (Gibco, Grand Island, USA), 1\% penicillin/streptomycin (Sigma Aldrich, P0781), and 10\% Fetal Bovine Serum (Gibco, Grand Island, USA). The whole medium was changed every three days until the cells reached an $80 \%$ confluency. ${ }^{15}$

Osteoblast cell culture MC3T3-E1 was treated with the following steps. First, the osteoblast culture was prepared in a $15 \mathrm{~mL}$ centrifuge tube. The culture was centrifuged for 5 minutes at 4900 RPM. The media was eliminated afterwards and the cell sediment was deposited. Subsequently, the incubation process was administered for three days at $370 \mathrm{C}$ and $5 \%$ of $\mathrm{CO} 2 .{ }^{8}$

After a three-day incubation process, the cells were ready to be harvested. The first step was preparing the petri dish tissue culture containing the confluence cells 
plus $1 \mathrm{~mL}$ EDTA trypsin. Then, it was stored in the incubator at $39^{\circ} \mathrm{C}$ for 5 minutes. After the incubation was completed, approximately $2 \mathrm{~mL}$ of media was taken and put into a Petri dish of tissue culture. The following procedure would be inserting it into a $15 \mathrm{~mL}$ centrifuge tube. Then, a centrifugation process was conducted at 4500rpm for 5 minutes which resulted in the cells settling at the bottom of the tube. Osteoblasts that had been successfully cultured were used as an MTT test indicator to determine the cytotoxicity of novel DDMM.

For morphological analysis, MC3T3-E1 cells were positioned into a 96-well plate. The viable cells were monitored using a fluorescence imaging. The CellD software from the photomicroscope (PX71, Olympus) was operated to verify the morphology of the cells throughout the culture.

\section{MTT Assay}

MTT test was carried out with the following stages. A pipette of $100 \mu \mathrm{L}$ cell in the media control wells, cell control and experimental groups. Then, a pipette of $10 \mu \mathrm{L}$ cells with a total of 5000-10,000 cells was put into a cell control well and treatment group/well Afterwards, they were moved into a 24-hour incubation process with a temperature of $37^{\circ} \mathrm{C}$ and $5 \%$ of $\mathrm{CO} 2$. After the incubation was completed, the media were disposed of and new media were added with approximately $100 \mu \mathrm{L}$ in the cell control and media control wells. The pipette in the treatment well contained approximately $50 \mu \mathrm{L}$ extract. On the other hand, the pipette in the treatment contained approximately $50 \mu \mathrm{L}$ media. After that, it was incubated for 24 hours at $37^{\circ} \mathrm{C}$ and $5 \%$ of $\mathrm{CO} 2$. The pipette of $10 \mu \mathrm{L}$ MTT reagents in all wells, then it was incubated for 4 hours at $37^{\circ} \mathrm{C}$ and $5 \%$ of $\mathrm{CO} 2$ pipette $50 \mu \mathrm{L}$ DMSO in all wells. Mitochondria in osteoblast cells would reduce MTT formazan salt and produce a purple colour. The last process was the incubation of ... ? For 10 minutes at $37^{\circ} \mathrm{C}$ which was followed with a process of determining the absorbance value with a wavelength of $540 \mathrm{~nm}$ using a microplate reader. ${ }^{6,8}$

After the test was conducted, the optical density (OD) value would appear from the microplate reader, which was used to determine the percentage of the cell's viability to proliferate in the treatment. This was calculated using a viability cell formula.

$$
\% \text { viability cell }=\frac{\text { OD treatment }- \text { OD media }}{\text { OD cell control }- \text { OD media }} \times 100 \%
$$

The $\%$ viability cell was the percentage of viable cells after treatment, OD treatment was Formazan OD value in each test sample, OD media was Formazan OD value in media control, and OD cell was Formazan OD value in cell culture as a positive control. The result for using the formula described above, OD value was used to compute the percentage of cells.

\section{Statistical Analysis}

After the percentage of viable cells was obtained, a normality test was applied with the Shapiro-Wilk method, a homogeneity test with the Levene's test method and a significance test with the independent $T$-test method to determine whether the difference in cell percentage between samples was significant $(p<0.05)$.

\section{Results}

\section{Morphology of Cell Culture}

After a three-day incubation, the morphology of MC3T3-E1 cells, was examined with a photomicroscope. The MC3T3E1 cells exhibited a rounded morphology. Thedensities began forming a monolayer with spindle-shaped cells and without distinct abnormal changes (Figure 1).

\section{MTT Assay}

The results of the MTT assay reveal the absorbance value of the experimental sample group, positive control group and negative control group. The mean absorbance of the positive control group is 0.536 , while the negative control group is zero. Furthermore the absorbance of the DDMM sample group is 0.464 , and the BPCM group mean is 0.516 . Based on the results, it is known that the DDMM group has a higher percentage than the negative control group. The BPCM group has a higher percentage than the novel DDMM group. The positive control group has the highest percentage of absorbance values (Figure 2).

\section{Statistical Analysis}

The percentage of live cells was statistically examined to prove the research premise. The Shapiro-Wilk test was employed to determine normality in this study $(\mathrm{p}>0.05=$ average distribution data). The Shapiro-Wilk test revealed that the data were normally distributed, with a p-value of 0.653 for the DDMM group and a p-value of 0.068 for the BPCM group.

The results of this study indicated the value of absorbance of different materials. In DDMM, the average percentage of living cells was $84.4 \%$, whereas, in the BPCM 

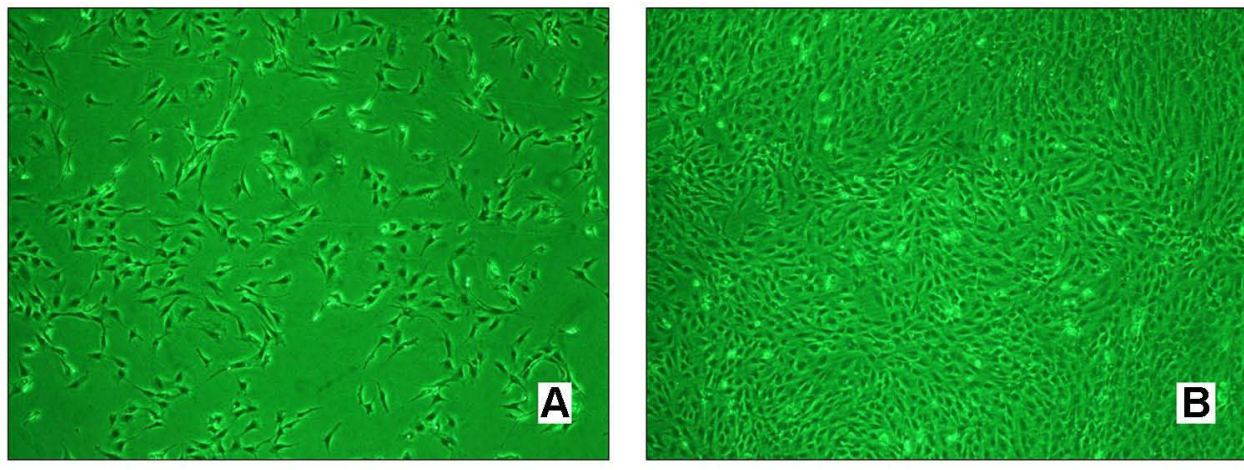

Figure I (A) Fluorescent images of the MC3T3-EI cells, most cells exhibited a rounded form, achieved confluency of around 50\% (B) well-spread cells displaying a polygonal morphology, achieved confluency of around $80 \%$.

Percentage of Cell Proliferation

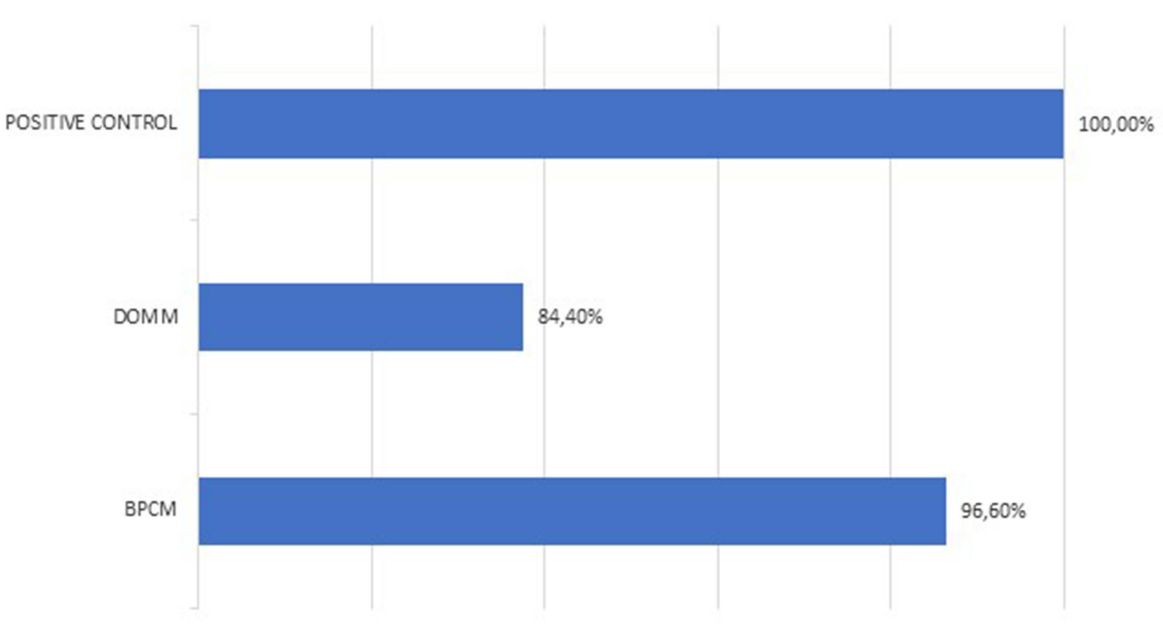

Figure 2 Table of absorbance value percentage of cell proliferation on each sample group.

membrane, it was $96.6 \%$ and the percentage of living cell was $100 \%$.

The average percentage of live cells in both membranes, DDMM and BPCM, was greater than 50\%. Therefore, both of membranes can be concluded to be nontoxic because they had a cell viability percentage of above $50 \%$ using the CD50 parameter. $^{11}$

In order to determine the homogeneity of the data, a homogeneity test is performed. The data were homogeneous according to Levene's test ( $p=0.091)$.

The data were regularly distributed and homogeneous, according to the normality and homogeneity tests. The Independent Sample T-test can be used to perform a variety of tests. The Independent Sample $T$-test revealed that no statistically significant difference existed between the DDMM and BPCM groups $(\mathrm{p}<0.05)$.

\section{Discussion}

DDMM is a bio-resorbed membrane derived from bovine dentine that has been demineralized. DDMM is a material with osteoinductive properties that are better than mineralised membranes because of the release of type 1 collagen matrix. Apart from humans, DDMM material can also be obtained from animals. Bovine dentine is easy to obtain, morphologically similar to human dentine, and possesses protein derivatives to support bone growth, namely BMP and TGF- $\beta .^{1,5,9,10}$

Performance measurement of mitochondrial dehydrogenase, also known as 3- (4,5-dimethyl-2-thiazolyl test) -2,5-diphenyl-2H-tetrazolium bromide (methyl thiazolyl tetrazolium; MTT), is a rapid assessment of cell proliferation and a colorimetric cytotoxicity test that can be lead into the cell metabolism or cell function measurement. The 
basic idea is that the tetrazole ring would be cut by mitochondrial dehydrogenase in the cytochrome $b$ and c sites of live cells. Purple formazan crystals are formed when the yellow water-soluble MTT is reduced. This substance dissolves in dimethyl sulfoxide and other organic solvents. However, it does not dissolve in water. The proportion of live cells and their activity are positively correlated with the quantity of crystals that formed. The percentage of viable cells and metabolic activity are reflected in the measurement of colorimetric absorbance. $^{12,13}$ The higher the value of optical density, the higher the cell viability will be. The optical density value of each treatment is used in the formula for calculating the percentage of viable cells.

In vivo cell attachment is influenced not only by the membrane material, but also by the implantation site and time, as well as the patient's age and condition. ${ }^{23}$ The rough surface structure of the membrane encourages attachment and proliferation of osteoblasts, whereas fibroblasts prefer to attach to smooth surfaces more easily. The overlapping fibrils or the poor protein binding capability cause the surface roughness. ${ }^{7,14}$ In addition, the incubation period of osteoblast cells did not achieve the desired target of the study because within 24 hours of incubation, this cell is still alive, while more than that time, the cell will lysis. ${ }^{12,16,24}$

The primary material of BPCM is pericardium that is composed of thick and dense fibrous tissue. ${ }^{14,17}$ Whereas DDMM is based on dentin which has tubules with a high level of porosity. DDMM has a more porous and rougher surface structure than BPCM. Thus, the osteoblast cell culture will be more attached to the surface of DDMM, and when the membrane is removed from the culture, many osteoblast cells are carried by DDMM, resulting in a lower absorbance value. Previous studies proved that the collagen content on BPCM was a factor that increased the initial attachment of cells, so the cell viability of BPCM was higher than novel DDMM. ${ }^{18-20}$

Collagen membranes has been demonstrated in several previous studies. It designed to reduce immunologic responses, including macrophage control. ${ }^{25,29}$

Based on this ability and the control of proinflammatory and anti-inflammatory characters, the collagen membrane is an innovative strategy to promote bone regeneration.

GBR's capacity to produce space might provide an impressive advantage in its ability in terms of maintaining and creating space for the new bone to spread. The intricate interfaces of cells in vivo cannot be recreated using an in-vitro experimental model. Although MC3T3E1 osteoblast cells are a mouse osteoprogenitor cell line, well considered and well raised in tissue culture. Some possible changes might occur between these cells, which could be generated orally from human osteoblasts. More research is needed to clarify the clinical validity of the results reproduced in this study and space preservation ability in the clinical setting. ${ }^{21,22}$

Although there are certain disadvantages to using resorbable membranes, such as the blockage of periosteal blood supply by the ingrowth of angiogenic cells with slow healing, resorbable membranes have more advantages than non-resorbable membranes. They provide for an outstanding handling, dramatically change in the surgical methods, boost regenerative capacity, and improve surgical results.

\section{Conclusion}

The present research showed that no significant difference between DDMM and BPCM as GBR materials ( $\mathrm{p}<0.05$ ) by MTT assays on osteogenic MC3T3-E1 cells viability. An increase in osteoblast cells was observed in the DDMM group cell viability of the BPCM group. From this study, it could be concluded that the DDMM membrane is non-toxic. These results indicate that DDMM may be a potential material to increase the number of osteoblasts. The study's implication will assist further related research in the path of DDMM application for bone regeneration through in vivo research.

\section{Acknowledgments}

The authors appreciatively acknowledge our research collaborators: Professor RM Coen Pramono Danudiningrat Universitas Airlangga and Professor Norifumi Nakamura Kagoshima University.

\section{Disclosure}

The authors report no conflicts of interest in this work. The authors do not have any financial interests, either directly or indirectly, in the products used in the study.

\section{References}

1. Um IW. Demineralized dentin matrix (ddm) as a carrier for recombinant human bone morphogenetic proteins (rhBMP-2). In: Novel Biomaterials for Regenerative Medicine. Singapore: Springer; 2018: 487-499. 
2. Susanto A, Susanah S, Priosoeryanto BP, Satari MH. Guided Tissue Regeneration Membrane for Periodontal Regeneration. Repository FKG Unpad; 2017:1-3.

3. Kamadjaja DB, Harijadi A, Soesilawati P, et al. Demineralized freeze-dried bovine cortical bone: its potential for guided bone regeneration membrane. Int J Dent. 2017;2017:1-10. doi:10.1155/2017/ 5149675

4. Nakashima M. The effects of growth factors on DNA synthesis, proteoglycan synthesis and alkaline phosphatase activity in bovine dental pulp cells. Arch Oral Biol. 1992;37(3):231-236. doi:10.1016/ 0003-9969(92)90093-N

5. Um I-W, Lee J-K, Kim J-Y, et al. Allogeneic dentin graft: a review on its osteoinductivity and antigenicity. Materials. 2021;14(7):1713. doi:10.3390/ma14071713

6. Khoswanto C, Arijani E, Soesilawati P. Cytotoxicity test of 40, 50 and $60 \%$ citric acid as dentin conditioner by using MTT assay on culture cell line. Dent J (Maj Ked Gigi). 2008;41(3):103-106. doi:10.20473/j.djmkg.v41.i3.p103-106

7. Plumb JA. Cell sensitivity assays: the MTT assay. In: Cancer Cell Culture. Humana Press; 2004:165-169.

8. Rothamel D, Schwarz F, Sculean A, Herten M, Scherbaum W, Becker J. Biocompatibility of various collagen membranes in cultures of human PDL fibroblasts and human osteoblast-like cells. Clin Oral Implants Res. 2004;15(4):443-449. doi:10.1111/j.1600-0501.2004.01 039.x

9. Soheilifar S, Soheilifar S, Bidgoli M, Torkzaban P. Barrier membrane, a device for regeneration: properties and applications. Avicenna J Dent Res. 2014;6(2):2-3. doi:10.17795/ajdr-21343

10. Johnson TB, Siderits B, Nye S, et al. Effect of guided bone regeneration on bone quality surrounding dental implants. $J$ Biomech. 2018;80:166-170. doi:10.1016/j.jbiomech.2018.08.011

11. Telli C, Serper A, Dogan AL, Guc D. Evaluation of the cytotoxicity of calcium phosphate root canal sealers by MTT assay. $J$ Endod. 1999;25(12):811-813. doi:10.1016/S0099-2399(99)80303-3

12. Wang H, Cheng H, Wang F, Wei D, Wang X. An improved 3-(4, 5-dimethylthiazol-2-yl)-2, 5-diphenyl tetrazolium bromide (MTT) reduction assay for evaluating the viability of Escherichia coli cells. J Microbiol Methods. 2010;82(3):330-333. doi:10.1016/j.mimet.20 10.06.014

13. Stockert JC, Blázquez-Castro A, Cañete M, Horobin RW, Villanueva Á. MTT assay for cell viability: intracellular localization of the formazan product is in lipid droplets. Acta Histochem. 2012;114(8):785-796. doi:10.1016/j.acthis.2012.01.006

14. de Santana RB, de Matos CML, Francishone CE, Van Dyke T. Superficial topography and porosity of an absorbable barrier membrane impacts soft tissue response in guided bone regeneration. J Periodontol. 2010;81(6):926-933. doi:10.1902/ jop.2010.090592

15. Yazid F, Kay ANM, Qin WY, Luchman NA, Wahab RMA, Ariffin SHZ. Morphology and osteogenic capability of MC3T3-E1 cells on granular hydroxyapatite scaffold. J Biol Sci. 2019;19 (3):201-209. doi:10.3923/jbs.2019.201.209
16. Wu C, Chen M, Zheng T, Yang X. Effect of surface roughness on the initial response of MC3T3-E1 cells cultured on polished titanium alloy. Biomed Mater Eng. 2015;26(s1):S155-S164. doi:10.3233/ BME-151301

17. Elgali I, Omar O, Dahlin C, Thomsen P. Guided bone regeneration: materials and biological mechanisms revisited. Eur J Oral Sci. 2017;125(5):315-337. doi:10.1111/eos.12364

18. Amruthwar SS, Janorkar AV. In vitro evaluation of elastin-like polypeptide-collagen composite scaffold for bone tissue engineering. Dent Mater. 2013;29(2):211-220. doi:10.1016/j. dental.2012.10.003

19. Suh H, Hwang YS, Song MJ, Lee WS, Han CD, Park JC. Behaviors of osteoblast-like cell (MC3T3-E1) on collagen grafted porous poly 1-lactic acid (PLLA) membranes with various pore sizes. 2000;37-44.

20. Takata T, Miyauchi M, Wang HL. Migration of osteoblastic cells on various guided bone regeneration membranes. Clin Oral Implants Res. 2001;12(4):332-338. doi:10.1034/j.1600-0501.2001.012004332.x

21. Chu C, Deng J, Sun X, Qu Y, Man Y. Collagen membrane and immune response in guided bone regeneration: recent progress and perspectives. Tissue Eng Part B Rev. 2017;23(5):421-435. doi:10. 1089/ten.teb.2016.0463

22. Wang HL, Miyauchi M, Takata T. Initial attachment of osteoblasts to various guided bone regeneration membranes: an in vitro study. $J$ Periodontal Res. 2002;37(5):340-344. doi:10.1034/j.1600-0765. 2002.01625.x

23. Haque N, Fareez IM, Fong LF, et al. Role of the CXCR4-SDF1HMGB1 pathway in the directional migration of cells and regeneration of affected organs. World J Stem Cells. 2020;12(9):938. doi: $10.4252 /$ wjsc.v12.i9.938

24. Haque N, Widera D, Govindasamy V, Soesilawati P, Abu Kasim NH. Extracellular vesicles from stem and progenitor cells for cell-free regenerative therapy. Curr Mol Med. 2021;21. doi:10.2174/ 1566524021666210125114828

25. Soesilawati P, Ambarani EL, Oki AS. Increased vascular endothelial growth factor (VEGF) expression in Wistar rat oral mucosa traumatic ulcer due to golden sea cucumber (stichopus hermanni) extract gel. Acta Med Philipp. 2019;53(6). doi:10.47895/amp.v53i6.667

26. Ku JK, Kim BJ, Park JY, et al. Effects of gamma irradiation on the measurement of hepatitis B virus DNA in dentin harvested from chronically infected patients. Ann Transl Med. 2020;8(6):314. doi: $10.21037 / \mathrm{atm} .2020 .03 .04$

27. de Dios Teruel J, Alcolea A, Hernández A, Ruiz AJ. Comparison of chemical composition of enamel and dentine in human, bovine, porcine and ovine teeth. Arch Oral Biol. 2015;60(5):768-775. doi:10.1016/j.archoralbio.2015.01.014

28. Um IW, Ku JK, Kim YM, et al. Allogeneic demineralized dentin matrix graft for guided bone regeneration in dental implants. Appl Sci. 2020;10(13):4661. doi:10.3390/app10134661

29. Soesilawati P, Tantiana,AZ Anti immunogenicity evaluation of bovine demineralized dentine membrane material. Mal $\mathrm{J}$ Med Health Sci. 2021;17(SUPP2):103-105. 


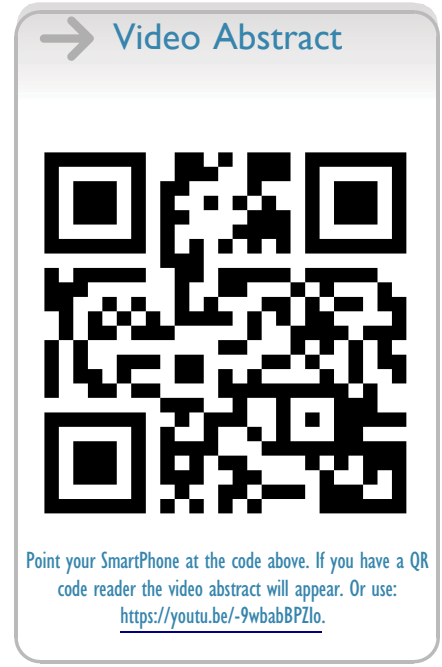

Clinical, Cosmetic and Investigational Dentistry

\section{Publish your work in this journal}

Clinical, Cosmetic and Investigational Dentistry is an international, peer-reviewed, open access, online journal focusing on the latest clinical and experimental research in dentistry with specific emphasis on cosmetic interventions. Innovative developments in dental materials, techniques and devices that improve outcomes and patien satisfaction and preference will be highlighted. The manuscript management system is completely online and includes a very quick and fair peer-review system, which is all easy to use. Visit http://www.dovepress.com/testimonials.php to read real quotes from published authors. 